\title{
Left Atrium Size, Quantitative
}

National Cancer Institute

\section{Source}

National Cancer Institute. Left Atrium Size, Quantitative. NCI Thesaurus. Code C80422.

A measurement obtained from radiographic image of the left cardiac atrium. 